\title{
BMJ Global Health Health system redesign for equity in maternal and newborn health must be codesigned, country led, adapted to context and fit for purpose
}

\author{
Claudia Hanson (D) , ${ }^{1,2}$ Peter Waiswa, ${ }^{3}$ Andrea Pembe, ${ }^{4}$ Jane Sandall, ${ }^{5}$ \\ Joanna Schellenberg (D) ${ }^{2}$
}

To cite: Hanson C, Waiswa P, Pembe A, et al. Health system redesign for equity in maternal and newborn health must be codesigned, country led, adapted to context and fit for purpose. BMJ Global Health 2020;5:e003748. doi:10.1136/ bmjgh-2020-003748

Received 18 August 2020 Accepted 19 August 2020

\section{SLinked}

- http://dx.doi.org/10.1136/ bmjgh-2020-002539

Check for updates

(C) Author(s) (or their employer(s)) 2020. Re-use permitted under CC BY-NC. No commercial re-use. See rights and permissions. Published by BMJ

${ }^{1}$ Global Public Health, Karolinska Institute, Stockholm, Sweden ${ }^{2}$ Department of Disease Control, London School of Hygiene and Tropical Medicine, London, UK ${ }^{3}$ School of Public Health, Makerere University, Kampala, Uganda

${ }^{4}$ Obstetric and Gynaecology, Muhimbili University of Health and Allied Sciences, Dar es Salaam, Tanzania

${ }^{5}$ Department of Women and Children's Health, King's College London, London, UK

Correspondence to Dr Claudia Hanson; claudia.hanson@ki.se
In this edition of BMJ Global Health, RoderDeWan and colleagues suggest ways in which we might rethink care models to close the equity gap in maternal and newborn health. ${ }^{1}$ Their analysis article follows from the work of the Lancet Global Health Commission on High-Quality Health Systems, proposing design reforms with quality at the centre. ${ }^{2}$ The authors suggest that all childbirth care services should be moved to hospitals in all countries, combined with improvements in (1) the quality of care provided in these facilities; (2) transportation from home to hospital; and (3) continuity of care through hub-and-spoke arrangements.

We agree in principle with the need to shift childbirth care services towards higher level facilities. The quality of care provided to women and their newborns in low and middle-income countries (LMICs) is inadequate. ${ }^{1}$ Economic development and advances in communication and transportation should redefine the paradigm of proximity to care. ${ }^{1}$ Also Kruk and colleagues estimated that more lives are lost today due to substandard care than due to limited geographical access. ${ }^{3}$ So it is important to rethink where and how childbirth care should be made available.

However, such health system redesign needs to respond to local needs and bottlenecksthat is, redesign must centre human resources, particularly midwifery providers; respond to the local context; and be fit for purpose. To cite Lynn Freedman, 'The point is not that global strategies, evidence-based guidelines, or high-level monitoring and accountability initiatives are inherently wrong or unnecessary. But when they consume most of the oxygen in the room, drowning out voices and signals coming from the ground, they distort both understanding and action.' 4
Redesigning maternal and perinatal care needs to be done with a view to strengthening district health systems in a sustainable and crisis-resilient manner-as the ongoing COVID-19 pandemic reminds us. To prompt an open and transparent debate, informed by local insight and strategies based on evidence, we present here our own thoughts and reflections on how to take this agenda forward.

First, Roder-DeWan and colleagues propose that the present strategy of promoting childbirth care in primary health facilities may be the primary reason for improvements in maternal and newborn survival being less than anticipated. Numerous studies indicate that primary facilities, which generally have a low case load, provide substandard care. ${ }^{5}{ }^{6}$ However most-if not all-of the present analysis is based on cross-sectional data; interpretation is inherently complicated by reverse causality and circular loops in thinking, as health planners wisely prioritise investments in equipment and upgrading of services of higher level and high case load facilities. As a result, we do not know the quality of the care that primary facilities could provide if they would be staffed and equipped according to standards. However, we agree that case load must be considered-although we believe there is still no consensus on what the preferred volume of cases in childbirth facilities should be. ${ }^{7}$

The discussion on the place of delivery is missing a debate on the skills of the providers. The skilled birth attendant strategy, which stems from the Millennium Development Goals era, was primarily informed by experience of midwifery ${ }^{8}$ based on the concept that skills and competences are the most important attributes for high-quality childbirth care. However, skilled birth attendant training 
in the past 20 years has often prioritised quantity over quality by opening fast-track 1-year or 2-year training, ${ }^{10} \mathrm{a}$ strategy which ignored the complexity of pregnancy care and in particular childbirth care.

In a study including almost 120000 pregnant women, Gabrysch and colleagues reported that, to their surprise, there was no evidence of better maternal or newborn survival for those living closest to a facility offering highquality care at birth, although there was evidence of a reduced risk of intrapartum stillbirth. ${ }^{11}$ This is a reminder that improving the quality of care means moving beyond the common concepts of facilities providing basic or comprehensive emergency obstetric and newborn care at primary or hospital levels, and requires a shift in focus to the provider instead. Human resources are the crucial factor underlying all approaches to care organisation. Midwives and nurse-midwives should be at the centre of a country-led, adapted-to-context, resilient and fit-for-purpose redesign.

We note that a Cochrane review of 15 trials in highincome countries of midwife-led continuity models of care with other models of care involving 17674 women suggests that women who received midwife-led continuity models of care compared with other models of care were less likely to have potentially harmful interventions such as episiotomies or instrumental births and more likely to have a spontaneous vaginal birth and increased satisfaction. Women were less likely to experience preterm birth and were at a lower risk of losing their babies. The review identified no adverse effects compared with other models. ${ }^{12}$ Countries such as India and Bangladesh are changing from training skilled birth attendants towards scale-up of midwifery training. ${ }^{13}$

In addition, there is more to be learnt from the integrated maternity system that exists, for example, in the UK, Netherlands, Scandinavia, Australia and New Zealand. Here midwives provide cost-effective maternity care in community and hospital settings. Childbirth care is offered in a range of settings to healthy women (home, hospital and midwife unit including free-standing or alongside an obstetric unit) with good outcomes. ${ }^{1415}$ It is important to note that the largest global study of outcomes by planned place of birth found a lower caesarean section rate in midwifery-led care systems compared with other settings ${ }^{14}$ an important finding in view of the debate on non-rational use of caesarean section.

It is timely that 2020 is the year of the nurse and the midwife: nurses and midwives must have the opportunity to be heard and to lead the further agenda on maternal and newborn health. Midwifery-led childbirth care services at an intermediate level of a district healthcare system, integrated into midwifery-based continuity of care, should be an alternative approach to shifting all births to a hospital. Midwifery-led continuity-based systems with midwifery-led childbirth care for low-risk women should be rigorously tested in LMIC settings.

Second, while we agree that many referral systems do not function, better communication and referral across the tiers of a health system must be central to a country-led, adapted-to-context, resilient and fit-forpurpose redesign. The examples which Roder-DeWan and colleagues provide to indicate how transport to a hospital may be improved, can also stimulate thinking on how referral between levels of a healthcare system may be improved. But whether transport starts at home or at a facility, past challenges will remain if there is too little emphasis on sustainable operational systems as reports on lack of fuel or driver suggest. ${ }^{16}$

Roder-DeWan and colleagues propose a hub-and-spoke system linking primary to hospital care. This is surprising: to our knowledge such systems already exist in most LMIC settings, where district health systems include linked primary care facilities and hospitals, comprising exactly such a hub-and-spoke system.

A country-led, adapted-to-context, resilient and fit-forpurpose redesign should strengthen these established systems, for women, children and men; cutting across all diseases and illnesses. Many district health systems are based on more than two tiers, and any change in strategy needs to build on these more nuanced systems. This strength should be harnessed. District medical officers and local health planners, with their rich local knowledge and insight, should drive the decisions on how and where high-quality childbirth care may best be delivered in their systems.

Third, we question the assertion that 'recent expansions in infrastructure and roads have put hospitals within reach of most families. This claim is based on analysis from six countries (Haiti, Kenya, Malawi, Namibia, Nepal and Tanzania) suggesting that over $70 \%$ of women live within a 2-hour journey time to a hospital providing emergency obstetric care. The analysis assumes ideal conditions, including that motorised transport would be readily available if needed, ignoring the problems of finding transport at night or longer travel times during the rainy season as the authors admit. ${ }^{17} \mathrm{~A}$ 2-hour journey time to childbirth care is unrealistic in many settings. Moreover, this is not the norm in high-income settings. In Germany, it is suggested that a hospital offering childbirth care should be within 20-30 min travel time. ${ }^{18}$

Roder-DeWan and colleagues also admit the need to establish more decentralised health centres with comprehensive emergency obstetric care services to reduce the journey time. In view of the population increase, particularly in Africa, establishing more hospitals is a forwardlooking strategy for maternal and perinatal health and other health needs. However, hospitals are large longterm investments. In Southern Tanzania, it took 8 years from laying the first bricks of new operating theatres within health centres to establish functioning services, and even then, not all operating theatres have the staff to provide continuous care.

There are examples of non-governmental organisationsupported initiatives where functioning services were developed faster and made more consistently available. ${ }^{19}$ However, midwifery-led birthing facilities equipped with functioning ambulance able to make transfers to a hospital with caesarean section services may be a less 
complex and more flexible approach; more responsive to the needs of women and their families. Geographical information systems can help find a local balance between quality and accessibility. ${ }^{20}$

While expanding hospital services remains a long-term vision, operational and practical medium-term strengthening is needed to fix the present quality of care and operational problems. And women should have a say: midwifery-led continuity models may provide the highest satisfaction among women and their families with lowest maternal and perinatal morbidity and mortality. ${ }^{12}$

The COVID-19 pandemic is critically disrupting access to hospital care throughout the world, and this prompts us to share another perspective: hospitals are typically overcrowded and beds in postnatal wards are often shared, making infection prevention and control even more challenging than ever. At present, women and families are avoiding hospitals, in fear of infection. Private transport has been severely interrupted. Creating resilient health systems means that quality care is also available in crisis. In Cambodia, community-based research respondents raised the lack of flexibility of the provision of childbirth care when floods were disrupting normality. ${ }^{21}$ Women and their families should not only be consulted as research respondents but continuously, so that end users are central to defining strategies. Women and their families should have a say indicating how far is too far.

In conclusion, although we concur with many of the arguments and conclusions, we believe that more discussion is needed and more options need to be rigorously tried and tested to develop sustainable district health systems which are fit for purpose and respond to needs of women, their babies, their families and centred around midwifery-based continuity of care.

Twitter Jane Sandall @SandallJane

Contributors $\mathrm{CH}$ conceived the first idea. $\mathrm{CH}$ and JS wrote the first full draft. All other authors commented and added. All authors agreed on the final version.

Funding The authors have not declared a specific grant for this research from any funding agency in the public, commercial or not-for-profit sectors.

Competing interests None declared.

Patient consent for publication Not required.

Provenance and peer review Commissioned; internally peer reviewed.

Data availability statement There are no data in this work.

Open access This is an open access article distributed in accordance with the Creative Commons Attribution Non Commercial (CC BY-NC 4.0) license, which permits others to distribute, remix, adapt, build upon this work non-commercially, and license their derivative works on different terms, provided the original work is properly cited, appropriate credit is given, any changes made indicated, and the use is non-commercial. See: http://creativecommons.org/licenses/by-nc/4.0/.

\section{ORCID iDs}

Claudia Hanson http://orcid.org/0000-0001-8066-7873

Joanna Schellenberg http://orcid.org/0000-0002-0708-3676

\section{REFERENCES}

1 Roder-DeWan S, Nimako K, Archana A, et al. Health system redesign for maternal and newborn survival: rethinking care models to close the global equity gap. BMJ Glob Health 2020.

2 Kruk ME, Gage AD, Arsenault C, et al. High-Quality health systems in the sustainable development goals era: time for a revolution. Lancet Glob Health 2018;6:e1196-252.

3 Kruk ME, Gage AD, Joseph NT, et al. Mortality due to lowquality health systems in the universal health coverage era: a systematic analysis of amenable deaths in 137 countries. Lancet 2018;392:2203-12.

4 Freedman LP. Implementation and aspiration gaps: whose view counts? Lancet 2016;388:2068-9.

5 Campbell OMR, Calvert C, Testa A, et al. The scale, scope, coverage, and capability of childbirth care. Lancet 2016;388:2193-208.

6 Kruk ME, Leslie HH, Verguet S, et al. Quality of basic maternal care functions in health facilities of five African countries: an analysis of national health system surveys. Lancet Glob Health 2016;4:e845-55.

7 Straneo M, Hanson C, Fogliati P, et al. Minimum obstetric volume in low-income countries. Lancet 2017;389:698.

8 De Brouwere V, Tonglet R, Van Lerberghe W. Strategies for reducing maternal mortality in developing countries: what can we learn from the history of the industrialized West? Trop Med Int Health 1998;3:771-82.

9 Pathmanathan I, Liljestrand J, Martins J, et al. Investing in maternal health. learning from Malaysia and Sri Lanka. Washington: The World Bank, 2003.

10 Hobbs AJ, Moller A-B, Kachikis A, et al. Scoping review to identify and map the health personnel considered skilled birth attendants in low-and-middle income countries from 2000-2015. PLoS One 2019;14:e0211576.

11 Gabrysch S, Nesbitt RC, Schoeps A, et al. Does facility birth reduce maternal and perinatal mortality in Brong Ahafo, Ghana? A secondary analysis using data on 119244 pregnancies from two cluster-randomised controlled trials. Lancet Glob Health 2019;7:e1074-87.

12 Sandall J, Soltani H, Gates S, et al. Midwife-led continuity models versus other models of care for childbearing women. Cochrane Database Syst Rev 2016;4:Cd004667.

13 World Health Organization. Maternal, newborn, child and adolescent health.. Available: https://www.who.int/maternal_child_ adolescent/topics/quality-of-care/midwifery/en/ [Accessed 6 Aug 2020]

14 Birthplace in England Collaborative Group, Brocklehurst P, Hardy P, et al. Perinatal and maternal outcomes by planned place of birth for healthy women with low risk pregnancies: the birthplace in England national prospective cohort study. BMJ 2011;343:d7400.

15 Scarf VL, Rossiter C, Vedam S, et al. Maternal and perinatal outcomes by planned place of birth among women with low-risk pregnancies in high-income countries: a systematic review and meta-analysis. Midwifery 2018;62:240-55.

16 Alwy Al-Beity F, Pembe AB, Kwezi HA, et al. "We do what we can do to save a woman" health workers' perceptions of health facility readiness for management of postpartum haemorrhage. Glob Health Action 2020;13:1707403.

17 Gage AD, Carnes F, Blossom J, et al. In low- and middle-income countries, is delivery in high-quality obstetric facilities geographically feasible? Health Aff 2019;38:1576-84.

18 Künert M. Welche Geburtsklinik für welche Schwangere? [Which maternity hospital for which pregnant women?]. Frauenarzt 2018;11:844-8.

19 Nyamtema AS, Mwakatundu N, Dominico S, et al. Enhancing maternal and perinatal health in Under-Served remote areas in subSaharan Africa: a Tanzanian model. PLoS One 2016;11:e0151419.

20 Fogliati $\mathrm{P}$, Straneo M, Brogi C, et al. How can childbirth care for the rural poor be improved? A contribution from spatial modelling in rural Tanzania. PLoS One 2015;10:e0139460.

21 Saulnier DD, Hean H, Thol D, et al. Staying afloat: community perspectives on health system resilience in the management of pregnancy and childbirth care during floods in Cambodia. BMJ Glob Health 2020;5:e002272. 